\title{
Agility literature review: Classifications, training and testing
}

\author{
J. M. SHEPPARD ${ }^{1} \&$ W. B. YOUNG ${ }^{2}$ \\ ${ }^{1}$ Australian Institute of Sport, Belconnen, ACT and ${ }^{2}$ School of Human Movement and Sport Sciences, University of Ballarat, \\ Ballarat, VIC, Australia
}

(Accepted 4 November 2005)

\begin{abstract}
At present, no agreement on a precise definition of agility within the sports science community exists. The term is applied to a broad range of sport contexts, but with such great inconsistency, it further complicates our understanding of what trainable components may enhance agility. A new definition of agility is proposed: "a rapid whole body movement with change of velocity or direction in response to a stimulus". Agility has relationships with trainable physical qualities such as strength, power and technique, as well as cognitive components such as visual scanning techniques, visual scanning speed and anticipation. Agility testing is generally confined to tests of physical components such as change of direction speed, or cognitive components such as anticipation and pattern recognition. New tests of agility that combine physical and cognitive measures are encouraged.
\end{abstract}

Keywords: Direction change, speed, anticipation, acceleration

\section{Introduction}

Sprint training is an integral part of the overall training for track and field athletes, as well as field and court sports. Most sprint training focuses on drills and conditioning to develop acceleration and top speed straight sprinting (Blazevich, 1997a, 1997b; Delecluse, 1997; Donati, 1996; Francis, 1997; Knicker, 1997; Luchtenbern, 1990; Sheppard, 2003, 2004; Young, 1995; Young, Benton, Duthie, \& Pryor, 2001a). Past research and reports have been published regarding sprinting phases, including the acceleration, maximal speed and speed endurance phases (Burggemann \& Glad, 1990; Enoka, 2002; Kyrolainen, Komi, \& Belli, 1999; Mann, 1981).

The current paradigm of speed development is undergoing change in the sport science community, wherein a greater emphasis is being placed not just on acceleration, top speed and speed endurance training, but also on change of direction speed drills (Fulton, 1992; Gambetta, 1996; Moreno, 1995; Sayers, 2000; Twist \& Benicky, 1996). This represents an emphasis on the specificity of training with specific movement patterns, as straight sprint training appears to have little or no influence on the improvement of sprinting that involves changes of direction (Young, McDowell,
\& Scarlett, 2001b). Additional support for this is evidenced by a weak relationship between straight sprint performance and change of direction speed performance (Baker, 1999a; Buttifant, Graham, \& Cross, 1999; Clark, Martin, Lee, Fornasiero, \& Quinn, 1998; Tsitskarsis, Theoharopoulus, \& Garefis, 2003; Young, Hawken, \& McDonald, 1996).

Many field and court sports involve some straight sprinting, but more often repeated short sprinting with changes of direction. The ability to sprint repeatedly and change direction while sprinting is a determinant of sport performance in field and court sports, as evidenced by time and motion analysis, validation of testing batteries for elite and non-elite performers, and coaching analysis for sports such as rugby (Docherty, Wenger, \& Neary, 1988; Meir, Newton, Curtis, Fardell, \& Butler, 2001), field hockey (Keogh, Weber, \& Dalton, 2003) and soccer (Reilly, Williams, Nevill, \& Franks, 2000). Considering that field and court sports generally include these changes of direction in response to a stimulus (e.g. another player's movement, movement of play or the ball), it would seem important to provide testing and training that mimics this demand to increase specificity.

This article is a review of the literature that is relevant to defining agility, its relationships with 
other trainable qualities, and the testing of agility. We propose a new definition of agility that recognizes both the cognitive and physical components involved in agility for sport.

\section{Defining agility}

At present, there is no consensus among the sports science community for a clear definition of agility. Agility has classically been defined as simply the ability to change direction rapidly (Bloomfield, Ackland, \& Elliot, 1994; Clarke, 1959; Mathews, 1973), but also the ability to change direction rapidly and accurately (Barrow \& McGee, 1971; Johnson \& Nelson, 1969). In more recent publications, some authors have defined agility to include whole-body change of direction as well as rapid movement and direction change of limbs (Baechle, 1994; Draper \& Lancaster, 1985).

Even more confusing has been the introduction of the term "quickness" (Baker, 1999a; Moreno, 1995), which is seemingly used interchangeably for both agility and change of direction speed. Quickness has been identified as "a multi-planar or multidirectional skill that combines acceleration, explosiveness, and reactiveness" (Moreno, 1995). This definition suggests that quickness consists of cognitive and physical reactive abilities and explosive acceleration. If this is an identifiable physical quality, then one might infer that quickness is a component of agility, as the proposed definition (Moreno, 1995) for quickness does not include deceleration or changing direction. However, the available literature includes skills and tests that involve changing direction and deems these to be quickness drills and tests (Baker, 1999a; Moreno, 1995).

Currently, the term quickness is used a great deal in North American sports settings, and has been the topic of several presentations and workshops marketed towards athletes and coaches. The term quickness is also used extensively on the worldwide-web in reference to training methods for fieldsport athletes. Although the exact definition of quickness is unclear, its use will be avoided in the current article, as it is seemingly vague.

In addition, the term "cutting" has been used with reference to a directional change during a sprint movement (Bernier, 2003; Besier, Lloyd, Ackland, \& Cochrane, 2001a; Besier, Lloyd, Cochrane, \& Ackland, 2001b; Colby et al., 2000; McClay et al., 1994). Unlike the term quickness, cutting seemingly refers only to the specific portion of a directional change where the athlete's foot contacts the ground to initiate the change of direction.

The difficulty in finding an accepted definition of agility could be the result of the multiple factors, from various disciplines within sports science, which influence agility performance. A biomechanist might view agility in terms of the mechanical changes involved in altering body position. A motor learning scientist in sports psychology might view agility in terms of the information processing involved in visual scanning, decision making and reaction to a stimulus to change directions, as well as the process involved in learning and retaining the appropriate motor skill. Strength and conditioning coaches might define agility in terms of the physical qualities involved in changing direction. The differences seen in definitions of agility could simply be due to the perspective of various authors, and their individual expertise and background. A comprehensive definition of agility would recognize the physical demands (strength and conditioning), cognitive processes (motor learning) and technical skills (biomechanics) involved in agility performance.

In 1976, Chelladurai proposed a thorough definition of agility, noting that although there was agreement on the importance of agility in many sports, there were many varied definitions of agility. Furthermore, Chelladurai noted that none of these definitions included appropriate recognition of the perceptual and decision-making components that are involved in many sports. The author outlined a classification of agility so that tasks were deemed to be simple, temporal (no spatial uncertainty, but temporal uncertainty), spatial (no temporal uncertainty, but spatial uncertainty), or universal (temporal and spatial uncertainty) (Table I).

Defining various forms of agility performance, such as simple, temporal, spatial and universal, is unique in the literature. In particular, movements like the sprint start in athletics, which are considered agility tasks (Chelladurai, 1976), could be described as involving reaction time and velocity, as reaction time is defined as the minimum time from the presentation of a stimulus to the onset of a response, with velocity being defined as the rate of change in position with respect to time (Enoka, 2002). However, in the context of Chelladurai's (1976) complete group of definitions, simple, temporal, spatial and universal agility provide a unique framework for the understanding of the demands of many sports. When viewed from their simplest to most complex, tasks can be classified into one of the four categories outlined by Chelladurai (1976). This framework could be useful for coaches and sport scientists to classify sporting skills, thereby allowing an improved understanding of the sub-components involved.

Most research on agility testing has applied the term "agility" to describe any dynamic sporting action that involves a change in body position (Draper \& Lancaster, 1985; Fulton, 1992; Hastad \& Lacy, 1994). The application of the term agility varies, but has included lunges (Cronin, McNair, \& 
Marshall, 2003), a 3-yard run forward and back from a stationary start (Hoyle \& Holt, 1983), climbing over and under a track and field hurdle (Alricsson, Harns-Ringdahl, \& Werner, 2001), sprinting forward, stopping and returning from a $180^{\circ}$ turn (Draper \& Lancaster, 1985), simple hopping movements (Booher, Hench, Worrell, \& Stikeleather, 1993), but most commonly sprinting with directional changes (Fulton, 1992; Gabbett, 2002; Gambetta, 1996; Meir et al., 2001; Reilly et al., 2000; Rigg \& Reilly, 1987; Twist \& Benicky, 1996). According to Chelladurai (1976), all of these movements could be classified as simple agility only, in that there is no temporal or spatial uncertainty involved.

Recently, Young, James and Montgomery (2002) outlined a comprehensive definition of agility as it related to running sports such as football codes. The researchers addressed the multi-faceted influences involved in agility performance. In particular, the authors outlined that there are two main components of agility - change of direction speed and perceptual and decision-making factors. Within these two main components, sub-components exist, as outlined in Figure 1.

Table I. Classifications of agility (modified from Chelladurai, 1976).

\begin{tabular}{|c|c|c|}
\hline Agility classification & Definition & Example of sporting skill \\
\hline Simple & No spatial or temporal uncertainty & $\begin{array}{l}\text { Gymnast's floor routine: pre planned activity, } \\
\text { initiated when the athlete desires, with movements } \\
\text { that the athlete has pre planned. Stimulus is the } \\
\text { athlete's own movement and the physical domain in } \\
\text { which they are executing the skill }\end{array}$ \\
\hline Spatial & $\begin{array}{l}\text { Spatial uncertainty, but timing of movement } \\
\text { is pre planned (temporal confidence) }\end{array}$ & $\begin{array}{l}\text { Volleyball or racquet sport service receive: the umpire } \\
\text { determines a narrow window of time wherein the } \\
\text { server must serve the ball to the opponent. However, } \\
\text { there is no certainty on the part of the receiver as to } \\
\text { where the service will be directed }\end{array}$ \\
\hline Universal & Spatial and temporal uncertainty & $\begin{array}{l}\text { Ice hockey or football: during offensive and defensive } \\
\text { plays, the athletes cannot anticipate with certainty } \\
\text { when or where opposition players will move to }\end{array}$ \\
\hline
\end{tabular}

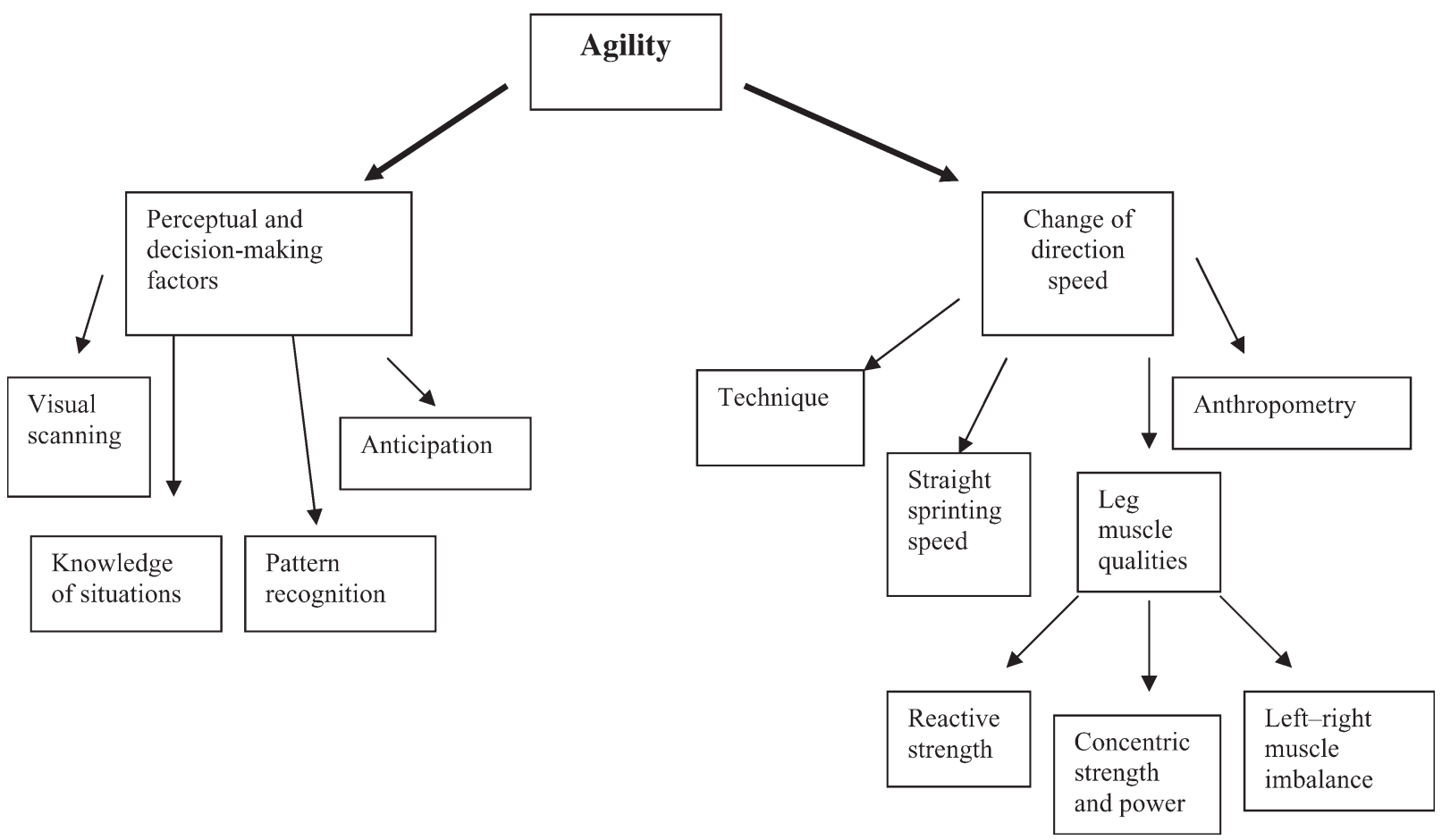

Figure 1. Universal agility components (modified from Young et al., 2002). 
In addition to their classification of agility for running sports, Young et al. (2002) included the term "change of direction speed" not only as a component of agility, but also to describe movement wherein no reaction to a stimulus is required. In other words, some conditioning exercises could be classified as change of direction speed exercises (sprints with changes of direction), while others could be classified as agility (sprints with directional changes in response to a stimulus).

Based on a review of literature that attempts to classify agility, it is obvious that several inconsistencies exist. There is clearly a trend among coaches and sport scientists to apply agility in a liberal manner, seemingly wherever a task involves dynamic movement requiring athleticism. This practice retards our understanding of the unique nature of skills that are applied in various settings. For example, if we are to accept that a pre-planned task such as an obstacle course is an agility task (Pandorf et al., 2003), yet we also accept that a reactive evasion drill for team sport athletes requires agility, how do we measure agility? And, within each circumstance, what factors are involved in agility performance? Sports scientists and coaches will be unable specifically to target the agility-related needs of various athletes if these subclassifications of agility are not understood.

A simpler definition of agility could be established by using an exclusion criterion, rather than an inclusion criterion such as that proposed by Chelladurai (1976) (Table I). While Chelladurai defined four levels within the context of agility, a more straightforward definition could assist coaches and sport scientists in communication, research, training and testing of agility.

If we accept that agility involves a response to a stimulus, then it is appropriate to eliminate the use of the classifications within agility that Chelladurai (1976) proposed. Tasks could be identified by describing the skill itself, using a biomechanical or physiological perspective. For example, a shot-put motion does not involve a response to any stimulus, although it has been described as an agility task (Chelladurai, 1976). This ability to pre-plan the skill, although requiring decision making, does not involve a response to a stimulus. From a cognitive perspective, this type of activity is referred to as a closed skill (Cox, 2002; Murray, 1996). Instead of classifying this as an agility task, we could describe the muscular and biomechanical motions involved. This will eliminate the grouping of such varying tasks into the classification of agility.

Another example often described as an agility running drill involves athletes running patterns around stationary objects (Gambetta, 1996). There is no reaction to a stimulus in these drills, and therefore training and testing in this manner will simply develop or evaluate change of direction speed, rather than agility performance.

Ultimately, the cognitive components involved in tasks that have traditionally been described as agility (e.g. athletics sprint start, shot put, zig-zag runs) differ greatly from tasks that contain significant uncertainty of time or space (e.g. reacting to a spike in volleyball, evading an opponent in football). To a great extent, the execution of many skills that have traditionally been deemed as agility have an automatic response, and therefore little or no uncertainty (Murray, 1996). From a cognitive perspective, these are closed skills and uncertainty is limited.

Open skills require athletes to respond to sensory stimuli around them, and the response is not an automated or rehearsed response (Cox, 2002). To provide further clarification, the example of a sprint start is useful. When a sprinter is set in the blocks, he or she will initiate movement in response to the audio stimulus of the starter's pistol. However, the response is one that can be rehearsed and therefore pre-planned. Although this skill has been referred to as an agility task (Chelladurai, 1976), it is not an open skill, and therefore is not an agility task.

By adopting an exclusive definition, the clarity and specificity of wording within the sporting community will increase. In other words, tasks are either accepted as agility tasks or they are not. We propose a new definition of agility for sport as follows: "a rapid whole-body movement with change of velocity or direction in response to a stimulus". This definition respects the cognitive components of visual scanning and decision making that contribute to agility performance in sport (Abernethy, Wood, \& Parks, 1999; Chelladurai, 1976; Young et al., 2002), as well as the physical performances involved in acceleration, deceleration and changes of direction in evading an opponent, sprints with changes of direction to contact a ball or player, or initiation of whole-body movement in response to a stimulus. To be considered an agility task, the movement will not only involve change in speed or direction, but must also be an open skill, wherein a reaction to a stimulus is involved and the movement is not specifically rehearsed.

This definition is therefore not dependent on directional change, as with previous definitions (Baechle, 1994; Chelladurai, 1976; Draper \& Lancaster, 1985; Johnson \& Nelson, 1969; Semenick, 1990). For example, agility could describe a soccer player who rapidly accelerates or decelerates in a straight line to evade an opponent, as this action is not pre-planned, would be in response to the movements of the opposing player (stimuli) and is an open skill. 


\section{Physical relationships with agility}

With a clear understanding of what an agility task is, we can proceed to examine the physical factors that can potentially be trained to improve agility performance. Almost all existing literature that has attempted to describe relationships with some measure of agility or training to improve agility has used a timed task involving one or more changes of direction, also known as change of direction speed.

\section{Relationship between straight sprinting speed and change of direction speed}

Anecdotally, it would appear that many strength and conditioning coaches believe that there is indeed a strong relationship between straight sprinting speed and change of direction speed, as some articles and many training sessions tend to address both qualities simultaneously. However, research evidence to support this view could not be found.

For example, in comparing the relationship between performance of the Illinois agility test and a 20-m sprint, Draper and Lancaster (1985) reported a statistically significant low to moderate correlation $(r=0.472)$. The Illinois agility test is a timed task involving some straight sprinting and multiple direction changes around obstacles.

Young et al. (1996) also investigated the relationships between speed and change of direction speed among Australian Rules football players. In this study, the researchers compared straight sprinting, sprinting while bouncing a football, sprinting with three planned directional changes at $90^{\circ}$ angles, sprinting with three planned directional changes at $90^{\circ}$ angles while bouncing a football, and sprinting with three directional changes at $120^{\circ}$ angles. The results supported the researchers' hypothesis in that the correlations between sprint and agility tests were all very low, indicating that sprinting, sprinting while bouncing a ball and sprinting while changing direction were distinct and specific qualities.

Using similar planned change of direction tests, Baker (1999a) examined the performance differences of elite and developmental rugby league players. The results of the study indicated that the two groups were similar in their straight running speed, but that the elite players performed better in tests that involved change of direction. The results of Baker's (1999a) study support those of Young et al. (1996), in that sprinting and agility are separate physical qualities. Additionally, similarly poor correlations $(r=0.33)$ were reported with soccer players (Buttifant, Graham, \& Cross, 1995) when comparing change of direction speed (CODS) test performance and straight sprint test performance. The participants were tested on a $20-\mathrm{m}$ straight sprint as well as a generic CODS test, involving four directional changes, of approximately $20 \mathrm{~m}$.

Based on the similar results presented by Baker (1999a), Buttifant et al. (1999), Draper and Lancaster (1985) and Young et al. (1996), straight sprint testing appears not to be related strongly to sprinting with changes of direction testing. Furthermore, and perhaps most importantly, straight sprint training does not improve performance in sprints with changes of direction (Young et al., 2001b). In this rare training study comparing sprint training with CODS performance (Young et al., 2001b), no significant improvements were reported in CODS performance after a chronic period of sprint training. If sprinting and sprinting with directional changes were strongly related, and if speed had a causal relationship with change of direction speed, the sprint training intervention used by Young et al. (2001b) would not only have improved straight speed (as was reported) but also change of direction speed. Generally, the more changes of direction, the less the transfer from the straight sprint training to change of direction speed. Also, CODS training had limited transfer to straight speed, providing clear evidence for the specificity of speed and CODS training (Young et al., 2001b). It might be hypothesized that straight sprint training would contribute even less to performance in an agility test that requires decision making.

Another consideration that is relevant to field and court sports involving complex skills (running with a ball, dribbling, etc.) is that sprinting while performing a skill further increases the complexity of the task. This increase in complexity affects an athlete's performance, as evidenced by weak relationships between straight sprinting ability and the ability to perform complex tasks such as dribbling a basketball (Tsitskarsis et al., 2003) or bouncing an Australian Rules Football (Young et al., 1996). Based on this consideration, tests and training that address skill demands could increase validity.

\section{Leg strength qualities and change of direction speed}

Many strength and conditioning coaches believe that strength and power measures and sprinting performance are strongly linked (Blazevich, 1997a, 1997b; Johnson, 1996; Luchtenbern, 1990; Sheppard, 2003, 2004), as correlations in the literature generally suggest moderate to strong relationships (Baker, 1999b; Young, McLean, \& Ardagna, 1995; Young et al., 1996). However, as noted previously, straightsprinting speed and speed while changing direction appear to be distinct physical qualities (Buttifant et al., 1999; Draper \& Lancaster, 1985; Young et al., 1996, 2001b). Therefore, one cannot infer that the 
apparent relationship between strength and straight sprinting can be extended to strength and change of direction speed, and an analysis of the relationship between leg muscle qualities and change of direction speed is warranted.

We will now examine literature that involves measures of muscular strength, power and reactive strength. Muscular strength measures have used loaded squat movements (Young et al., 1996) as well as an isokinetic squat (Negrete \& Brophy, 2000). Power measures of the lower extremity have generally utilized counter-movement vertical jumps (Negrete \& Brophy, 2000; Webb \& Lander, 1983; Young et al., 1996) and continuous vertical jumps (Djevalikian, 1993). Reactive strength, a measure of the ability to change rapidly from an eccentric to a concentric action, has been measured using a depth jump from various drop heights (Djevalikian, 1993; Young et al., 1996, 2002).

Change of direction speed and leg muscle strength and power

Young et al. (1996) found low $(r=0.01)$ and nonsignificant correlations between a $20-\mathrm{m}$ sprint with three $90^{\circ}$ directional changes and a countermovement jump loaded with an additional $50 \%$ of the participant's body weight. As the load was considered to be relatively high for a counter-movement jump, the authors deemed this protocol to be a strength measure. Young et al. (1996) also found low correlations $(r=-0.10)$ between an unloaded counter-movement jump and the 20-m CODS test. Similarly, Djevalikian (1993) reported low $(r=0.15)$ and non-significant correlations between power measures (15-s vertical jump performance) and a "boomerang run" that involved seven changes in direction: four $90^{\circ}$ turns and three $180^{\circ}$ turns (the test is run in both directions, providing a time to completion for a trial involving entirely right turns and a trial involving entirely left turns).

Webb and Lander (1983) used a single vertical jump and a single standing broad jump in comparison with an L-run change of direction speed test. Again, low and non-significant correlations were reported for both the standing broad jump $(r=-0.35)$ and the vertical jump $(r=-0.19)$ in relationship with the L-run for change of direction speed.

Young et al. (2002) correlated an 8-m sprint with directional changes with an isokinetic squat for power set at $40^{\circ}$ per second. A low and nonsignificant relationship $(r=0.34)$ was reported between the two variables. In contrast, Negrete and Brophy (2000) reported moderate and significant correlations $(r=-0.60 ; P<0.05)$ between singleleg isokinetic squat strength and a complex, multidirectional CODS task.
Based on the results of Djevalikian (1993), Webb and Lander (1983) and Young et al. (1996, 2002) (but see Negrete \& Brophy, 2000), concentric strength and power measures appear to be poor predictors of change of direction speed. Perhaps the difference observed between these studies is the nature of the task used to evaluate change of direction speed. Negrete and Brophy (2000) used a complex multi-directional task over short distances, whereas the others (Djevalikian, 1993; Webb \& Lander, 1983; Young et al., 1996, 2002) used sprint tests that involve some straight sprinting and changes of direction while sprinting. It could be that the CODS and sprint tasks adopted by these other researchers involved a greater amount of variability in acceleration and deceleration before changing direction and differences in technique compared with the shorter distances used by Negrete and Brophy (2000). This variability of running speed and technique in the sprint/CODS tasks could account for the weaker relationship with strength and power qualities, whereas with a test of lower variability in technique and less distance covered, there may simply be fewer physical factors to account for performance, resulting in a stronger relationship.

It would appear that strength and power measures have an influence on change of direction speed (Negrete \& Brophy, 2000), but that this relationship might only be observable when comparing tasks involving changes of direction speed over short distances. One might then infer that for sports such as badminton, and for field sport players involved in changes of direction over short distances (e.g. soccer goalkeeping), strength and power measures have a stronger relationship with changes of direction speed than athletes who perform directional changes with higher speeds over longer distances (soccer forward). However, this is not entirely clear. Further research on the effect of strength and power training on various measures of change of direction speed (addressing both sprints and directional changes as well as short-distance directional changes) would increase our understanding of the relatedness of strength and power with change of direction speed. It would also appear to be fruitful to investigate the relationship between change of direction speed and agility with other forms of muscle strength testing, such as eccentric protocols. Eccentric muscle function could have a strong relationship with deceleration, which, as previously established, is a component of field running and court sports.

\section{Relationship between bilateral reactive strength and change of direction speed}

Djevalikian (1993) investigated the relationship between reactive strength and change of direction 
speed. A statistically significant $(P<0.05)$ correlation $(r=0.42)$ was reported between the depth jump measure of reactive strength and the boomerang CODS task. However, Young et al. (1996) found a low $(r=0.36)$ and non-significant correlation between a drop jump and a 20-m sprint with three directional changes. Similarly, Young et al. (2002) reported non-significant correlations $(r=-0.47)$ between a depth jump and sprints with changes in direction.

Young et al. (2002) suggested that reactive strength, due to its stretch-shortening cycle (SSC) involvement, is a better predictor, or at least has a stronger relationship with change of direction speed. This viewpoint receives some support from the results of Djevalikian (1993), but not those of Young et al. (1996).

\section{Unilateral muscle strength and power qualities and change of direction speed}

Djevalikian (1993) examined the relationship between concentric muscle power strength imbalances between the right and left leg, and changes of direction while driving off the weaker leg. In other words, if an individual is weaker on the left leg, would he or she move more slowly to the right due to the push-off action of the left leg? The results suggested that there was no significant relationship between concentric muscle power and change of direction speed.

However, Young et al. (2002) reported that lowerextremity muscle imbalances influence change of direction speed. Their participants were found to be significantly slower in changing direction off the weaker leg when performing a unilateral drop jump test for reactive strength. The authors suggested that this was due to the similar push-off action of the drop jump (reactive strength movement) and that of a dynamic push-off in changing direction while sprinting.

Interestingly, there was little evidence of a strong relationship between bilateral strength and power (Djevalikian, 1993; Webb \& Lander, 1983; Young et al., 1996, 2002). Furthermore, studies of unilateral concentric power did not report strong correlations (Djevalikian, 1993; Young et al., 2002). However, when investigating unilateral reactive strength, perhaps more specific to the reactive push-off action involved in changing direction, results indicated a stronger relationship (Young et al., 2002).

Based on research findings (Baker, 1999b; Delecluse et al., 1995; Kukolj, Ropret, Ugarkovic, \& Jaric, 1999; Young et al., 1995, 1996), it is clear that strength and sprinting are related. However, it would appear that this relationship does not extend to sprints with directional changes (Baker, 1999b;
Negrete \& Brophy, 2000; Webb \& Lander, 1983; Young et al., 1996). In addition, typical power measures are not strong predictors of CODS performance (Djevalikian, 1993; Negrete \& Brophy, 2000; Young et al., 1996, 2002).

Based on the finding of Young et al. (2002), however, it would appear that reactive strength imbalances are a good predictor of imbalances in performance of change of direction sprints off the stronger and weaker leg. These authors suggested that future research should focus on an examination of the effects of training methods known to reduce unilateral reactive strength muscle imbalance (Knight, Cohen, \& Woodward, 2002; Kuhn, 1993) and its effect on agility performance.

\section{Anthropometry and change of direction speed}

Very little research has attempted to correlate anthropometric variables and change of direction speed performance. Theoretically, factors such as body fat and body segment lengths may contribute to agility performance. In comparing two athletes of equal total body mass, the fatter athlete will have less lean mass to contribute to the speed requirements of agility performance. In addition, the fatter athlete will have a greater mass of excess fatty tissue (not lean body mass) and inertia, thereby requiring greater force production per unit of lean mass to produce a given change in velocity or direction (Enoka, 2002).

Test batteries have revealed that athletes in sports such as rugby and soccer, who perform better on CODS tests, tend also to have lower body fat (Gabbett, 2002; Meir et al., 2001; Reilly et al., 2000; Rigg \& Reilly, 1987). However, this does not indicate a causal relationship. In fact, direct correlations between change of direction speed and body fat were not performed in the aforementioned studies. Indeed, the one study that did involve correlations of body fat and change of direction speed in rugby players found that the two variables were not strongly correlated $(r=0.21)$ (Webb \& Lander, 1983). Based on the results of these studies, we can only infer that low body fat and high speed in changing direction are important for success in the sports examined. The relationship between these two variables is unclear.

Other factors that could potentially be related to CODS performance are height, relative limb lengths, and the height of the athlete's centre of gravity. Some research has suggested that limb length has a relationship with certain sporting tasks, such as lunges typical of directional changes in tennis (Cronin et al., 2003). Comprehensive investigations into anthropometric factors and change of direction speed have yet to be performed.

An individual with a low centre of gravity could conceivably be able to apply horizontal force more 
quickly than a taller athlete, because they would require less time to lower their centre of gravity in preparation for a lateral direction change. This could mean that a faster change of direction is possible. It would appear fruitful to investigate this possibility using quantitative biomechanical measurement techniques.

\section{Technique}

Running technique has been suggested to play a key role in the performance of sprints with directional changes (Bompa, 1983; Sayers, 2000). In particular, a forward lean and low centre of gravity would appear essential in optimizing acceleration and deceleration, as well as increasing stability. The stability afforded by a low centre of gravity, as opposed to the upright stance and high centre of gravity of track and field sprinters (Francis, 1997), allows more rapid changes of direction, because to change direction at higher speeds, athletes must first decelerate and lower their centre of gravity (Sayers 2000). In other words, Sayers (2000) was suggesting that because sprinting with a high centre of gravity (as seen in track and field technique) requires postural adjustments (lowering of the centre of gravity and shortening stride lengths) and deceleration before changing direction, athletes in sports that require frequent changes of direction should run with a lower centre of gravity, greater forward lean and perhaps shorter stride lengths than athletics sprinters.

Review of the opinions proposed by Sayers (2000) reveals the greater need for specificity between training for sprinting and training for speed and agility in sports that require changes of direction. However, the biomechanics of straight-sprint training of the acceleration phase in athletics is similar to that proposed by Sayers (2000). In fact, a pronounced forward lean and low centre of gravity is an integral part of acceleration in sprinting for athletics (Francis, 1997; Mann, 1981), which is similar to that in agility sports (Sayers, 2000). The obvious exception would be that in athletics, sprinters are taught to keep their visual focus low (looking downward) for a portion of the acceleration phase (Francis, 1997), while in agility sports, visual scanning of the court or playing field is continuous.

In addition, sprinters might purposefully accelerate under greater control, in that they do not necessarily aim to achieve top speed as quickly as possible, but favour a controlled acceleration (Francis, 1987). In most running sports, sprints are generally short and of varying distances. Athletes in these sports will accelerate as much as possible in the shortest period of time. In the case of a $100-\mathrm{m}$ sprint, but especially a $200-\mathrm{m}$ sprint, the sprinter accelerates for a large portion of the race, aiming to achieve top speed late in the race, thereby minimizing the fall off in speed near the end of the race. Although it is commonly accepted that elite sprinters accelerate for longer periods simply because they also have higher top speeds that take longer to reach, tactical advice also involves controlling acceleration so that top speed is reached at an optimal time for overall race performance. The difference seen between athletics sprinting and sprinting in other sports is that the athletics sprint can be planned and strategy can play a role, whereas with the football codes, for example, short sprints occur throughout the game and cannot be pre-planned. Therefore, sprint training for sports other than athletics should include the need to accelerate, reaching the highest speed possible in the shortest time period (in addition to including relevant cognitive and skill demands).

In an examination of knee-joint loads comparing unplanned and planned change of direction, differences in specific approach-speed technique were observed (Besier et al., 2001a, 2001b). When participants were required to react to a light stimulus to change direction, the loads on the knee were increased, which was thought to be related to a suboptimal posture imposed by the time-stress in reacting to the stimulus and changing direction. This implies that postural techniques differ between planned and unplanned changes of direction.

Specific quantitative research of techniques in sprints for field sports, and sprints involving change of direction speed, is non-existent. Research quantifying stride length and biomechanical differences between high and low achievers in sprints with directional changes would appear fruitful.

\section{Testing agility}

The vast majority of tests purported to assess agility are tests for change of direction speed, as acknowledged by Ellis et al. in Gore (2000, p. 132):

The basic movement patterns of many team sports require the player to perform sudden changes in body direction in combination with rapid movement of limbs... The ability of the player to use these maneuvers successfully in the actual game will depend on other factors such as visual processing, timing, reaction time, perception, and anticipation. Although all these factors combined are reflected in the player's on-field "agility", the purpose of most agility tests is simply to measure the ability to rapidly change body direction and position in the horizontal plane. 


\section{Tests of change of direction speed}

In their review of the literature, Draper and Lancaster (1985) found no valid attempts at evaluating agility. The Illinois agility test (Cureton, 1951; Hastad \& Lacy, 1994) (Figure 2), 20-m sprint, upand-back test and the 505 test (Figure 3) were compared. At the time, the Illinois test was considered a standard test of agility. The researchers concluded that the 505 test was the most valid test of agility examined because it resulted in the highest correlation with acceleration in the turning phase of

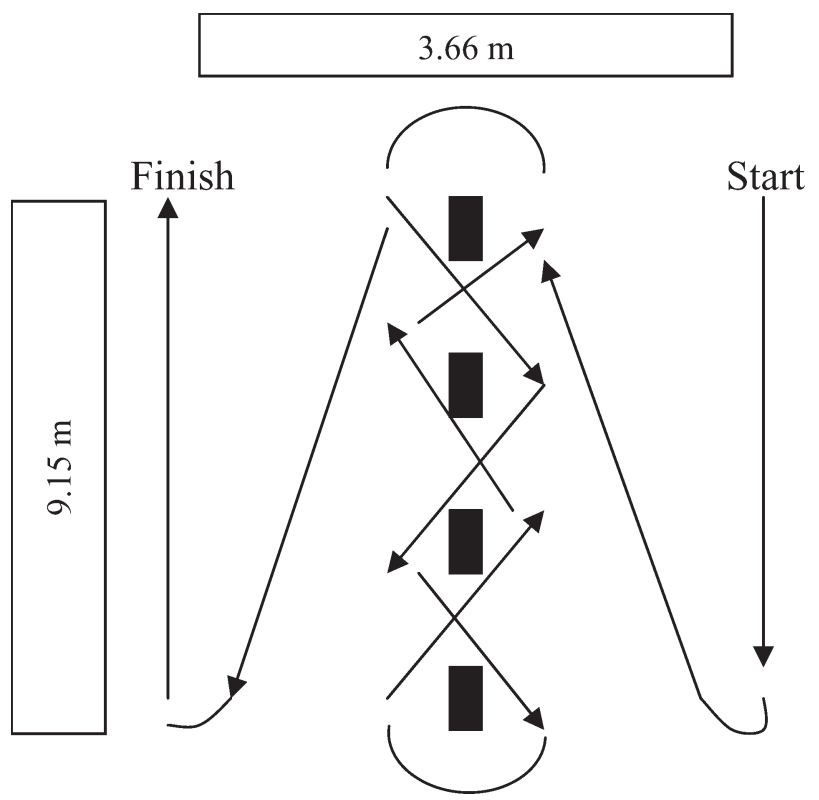

Figure 2. Illinois agility test (after Cureton, 1951). the test, but did not correlate highly with velocity. Draper and Lancaster (1985) deemed the Illinois agility test to be less valid than the 505 test, as it correlated strongly with top speed. The authors' viewpoint was that agility tests should be independent of top speed, whereas acceleration was more related to the demands of a change of direction and re-acceleration.

Draper and Lancaster (1985) did not consider any decision-making factors in their test design of agility. In fact, they accepted traditional definitions for agility that do not address perceptual factors (Baumgartner \& Jackson, 1975). Both the 505 and the up-and-back test involved pre-planned movements.

The 505 test was designed with the demands of cricket in mind. In the 505 test, the athlete sprints forward to a line $5 \mathrm{~m}$ ahead and pivots $180^{\circ}$ before returning to the start position (Figure 3). This test is especially appropriate for cricket batsmen, as the movement patterns are similar to those used by batsmen running between the wickets. However, the test has been used for other sports requiring change of directions and agility, such as netball (Gore, 2000).

The common theme in the tests of agility used by Baker (1999a), Draper and Lancaster (1985), Webb and Lander (1983) and Young et al. $(1996,2002)$ is that there is no stimulus present, and therefore none of these tests requires any cognitive and reactive component. Although there is great variation in the tests used, none of these studies involved tests requiring a reaction to a stimulus with a change of direction or movement.

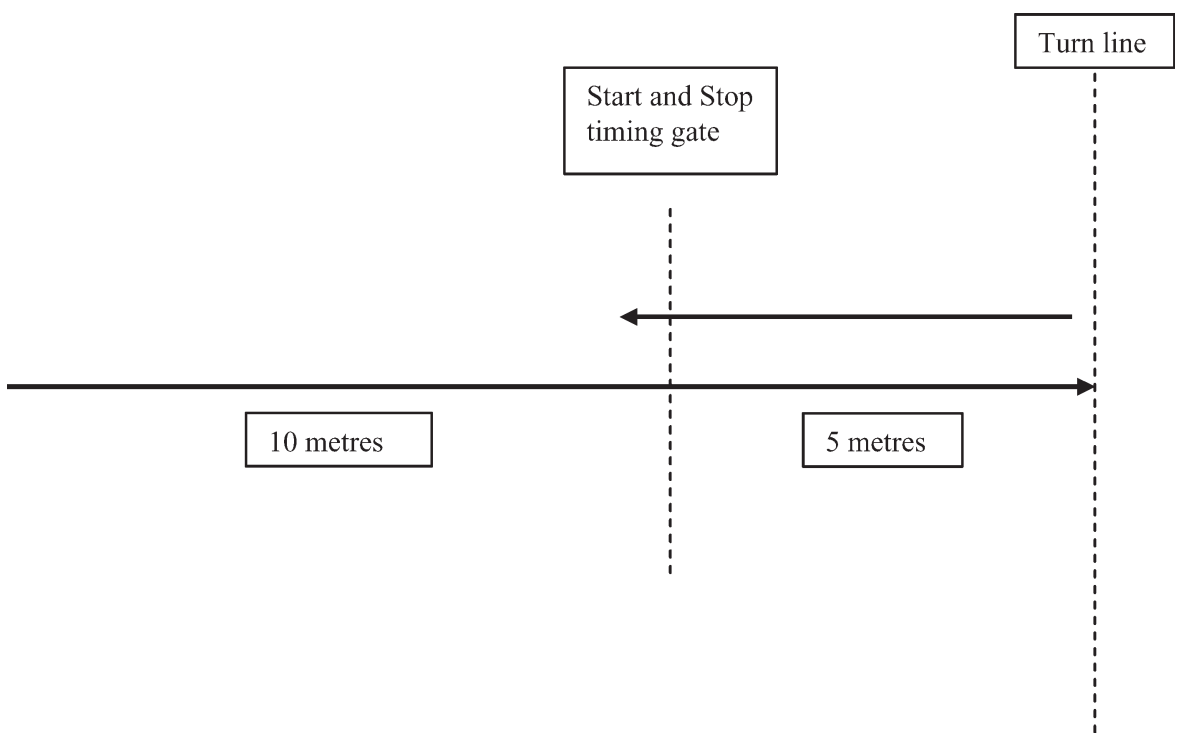

Figure 3. The 505 test of agility (after Draper \& Lancaster, 1985). 


\section{Cognitive considerations when testing agility}

Chelladurai, Yuhasz and Sipura (1977) examined the reactions of participants using an apparatus that triggered a display of several lights. Upon triggering the activator switch, the participant was exposed to one of several variations in illumination of the light bulbs on the display. The participant had to move quickly off the reaction mat to a switch below the bulb, press the switch (which turned the bulb off) and then return to the start area and press the activator switch again to stop the timer. The reaction times measured using this apparatus included total time of the task, forward time (time from leaving the mat to touching the switch below the bulb) and return time (time taken to return from the bulb switch to the mat). Based on the classifications provided by Chelladurai (1976), this apparatus tested universal agility, as the timing of the stimulus was uncertain, and there was little confidence in where the participant was to move in response (indicating both spatial and temporal uncertainty).

Although this apparatus was a significant step forwards in providing a stimulus in agility testing (i.e. responding to a light bulb), there is no means of including sport-specific perceptual and decisionmaking components such as recognition of movement patterns. For this reason, the apparatus is unlikely to be valid in differentiating elite and nonelite sport performers.

Hertel, Denegar, Johnson, Hale and Buckely (1999) assessed the reliability of a commercially available test apparatus for universal agility performance the Cybex Reactor (Cybex Corp., Ronkonkoma, NY). The test device consists of 14 target sensors on the floor of the training facility. These sensors are interfaced with a small video monitor and a computer terminal. The computer terminal contains a multitude of pre-programmed scenarios that require the participant to react to the video prompts on the monitor and move to the corresponding target on the floor, before being presented with the next stimulus.

As with any electronic stimulus device, the participant is exposed to a two-dimensional and generic stimulus. The light image does not resemble a stimulus that is present in sport. In addition, the generic pattern of targets (14 targets evenly spaced with the first two rows containing 4 targets each and the third row containing 6 targets) does not simulate sporting movements.

Cognitive research suggests that the anticipatory cues of high-performance athletes are linked directly to specific cues displayed by opponents within their sport (Abernethy \& Russell, 1987; Abernethy et al., 1999; Farrow, Chivers, Hardingham, \& Sachse,
1998). It has been suggested that elite performers differ from non-elite performers in their ability to use more clues earlier in the execution of a skill when anticipating an opponent's movements (Abernethy \& Russell, 1987). Therefore, tests that involve generic cues are likely to be limited in their ability to distinguish between elite and non-elite performers in a sport that requires a reaction to highly specific stimuli.

It is important to be aware of the informationprocessing demands of tasks in each sport. For some tasks, there is no need for a response to a stimulus, whereas others require that skills be executed in response to a stimulus. The more complicated the stimulus, the longer the response delay, based on the information-processing demands (Cox, 2002) (Figure 4).

Specificity of the stimulus presentation is important, as anticipatory expertise appears to be dependent on the specific stimulus used to test this quality (Abernethy \& Russell, 1987; Muir, 1996; Tenenbaum, Levy-Kolker, Sade, Lieberman, \& Lidor, 1996). When considering the human information-processing model, a stimulus produces specific mental operations that are based on the individual's retrieval of stored memory information before initiating a response. The accuracy and speed of this response will be dependent on the previously stored information specific to that situation (Cox, 2002). In other words, if the test stimulus is not adequately specific to the sport setting, then the measurement of response time will not be valid in measuring sporting expertise, because the participant will not necessarily have memory storage that involves the generic stimulus (Cox, 2002). Furthermore, if the information (stimulus) is either overly simple or complex compared with the demands of the sport, the response time measurement will also be invalid, as the complexity of the stimulus is also a key determinant of processing time (Murray, 1996).

Recently, at the Australian Institute of Sport in Canberra, D. Farrow and W. B. Young (personal communication) have developed an agility test protocol that addresses sport-specific movement patterns (Figure 5). This protocol uses pre-recorded video of various movements in netball as the stimulus for the participant. The participant triggers the playing of the video when the athlete's body breaks a timing beam on a set of timing lights. The athlete is then required to make a decision to move either left

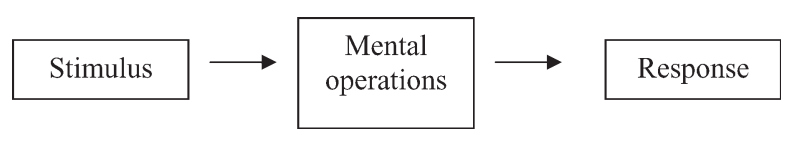

Figure 4. The information processing model (after Cox, 2002). 
Screen with life-size image
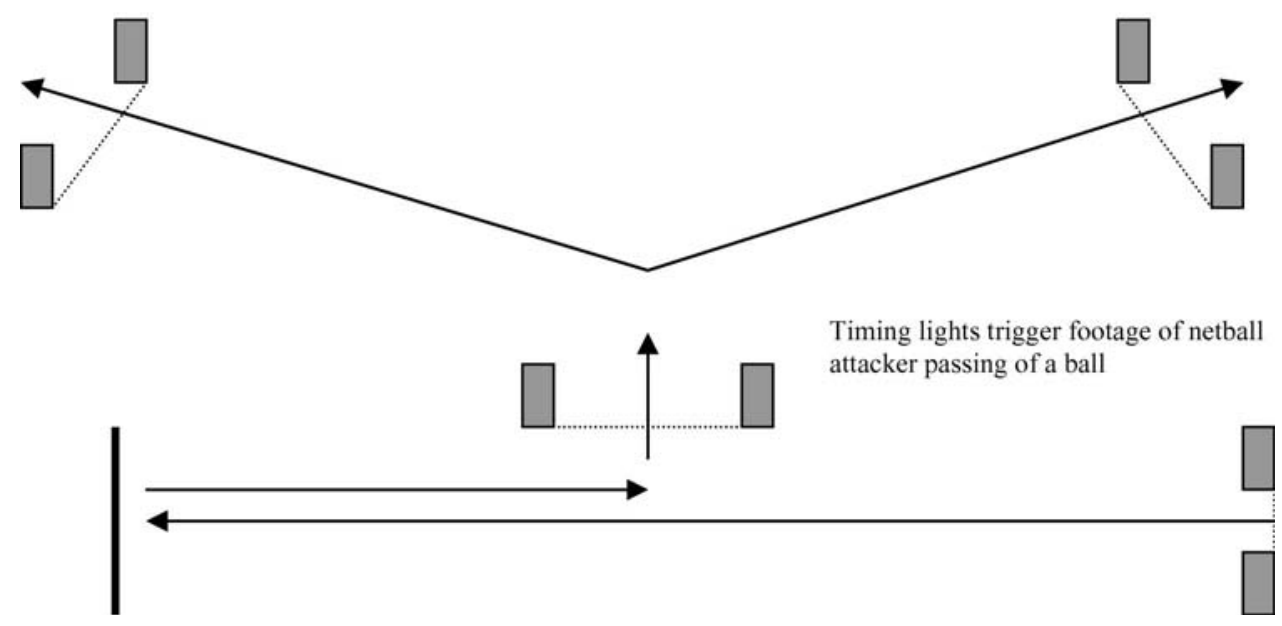

Figure 5. The reactive agility test for netball (D. Farrow and W. B. Young, personal communication).

or right in response to the video stimulus. The trial ends when the athlete's body breaks the timing beam on the left or right side of the test area.

Initial results (D. Farrow, W. B. Young, \& L. Bruce, unpublished) with this agility test indicated that the high-performance netball players initiated a change of direction movement before ball release due to anticipation of the offensive player's movements on the video screen. In contrast, the low-performance netball players exhibited a longer decision time and inferior total times. Interestingly, a planned version of this test, requiring a similar movement but no with no response to the video stimulus (the participants were told which direction to run to and did not have to anticipate and make decisions in response to the video), did not distinguish between the two groups of netball players. Furthermore, the correlation between the planned version and reactive version of the test was only moderate, indicating the two tests assessed somewhat different qualities.

While this test is probably the first to use a sportspecific stimulus to determine a directional change, it has significant limitations. Teams do not generally have access to high-speed cameras and the advanced multi-media equipment necessary to record, time and display the images required for the presentation of the stimulus. To date, the technology has only been applied to netball, and a different set of video images would be required for any other sport. In addition, although the stimulus is displayed as a fullsize image, it is presented in a two-dimensional format, which might limit the amount and specificity of cues available to which the athlete is to react.

\section{Conclusions}

Based on a review of the current paradigm of agility classifications, training and testing, there is a need within the sporting community to recognize what agility involves, how it is trained and what characteristics are being assessed using existing tests of agility. As noted in the review of existing tests, many involve no decision-making or reactive component and could be better described as change of direction speed tests as proposed by Young et al. (2002).

To avoid confusion and to encourage the application of more appropriate terms, a new definition involving an exclusive criterion has been proposed (Table II). This definition recognizes the cognitive components involved in agility, and does not make sub-classifications for tasks that do not involve this cognitive component.

Agility performance does not appear to be strongly linked with straight-speed components (Baker, 1999a; Buttifant et al., 1999; Tsitskarsis et al., 2003; Young et al., 1996). Essentially, speed and agility are distinct physical qualities, and speed training does not appear to enhance change of direction speed (CODS), and CODS training does not appear to enhance speed (Young et al., 2001b). Therefore, training for change of direction speed and agility must involve highly specific training that recognizes the specific demands of the sport.

At present, and with few exceptions (D. Farrow \& W. B. Young, personal communication), researchers, coaches and sport scientists are limited to the measurement of speed and change of direction 
Table II. Criteria for the classification of agility.

\begin{tabular}{lc}
\hline Agility & Other physical or cognitive skills \\
\hline - Must involve initiation of body movement, change of & - Entirely pre planned skills such as shot put classified by their \\
direction, or rapid acceleration or deceleration & skill function rather than included as a type of agility \\
- Must involve whole body movement & $\begin{array}{l}\text { Running with directional changes classified as change of } \\
\text { direction speed (CODS) rather than agility or quickness }\end{array}$ \\
- Involves considerable uncertainty, whether & - Closed skills that may require a response to a stimulus \\
spatial or temporal & [e.g. the sprint start in response to the starter's pistol is \\
- Open skills only & pre planned (closed), and therefore is not agility] \\
- Involves a physical and cognitive component, such as & \\
recognition of a stimulus, reaction, or execution of a \\
physical response
\end{tabular}

without cognitive challenges (Baker, 1999a; Draper \& Lancaster, 1985; Fulton, 1992; Pyne, 2001), with a physical measure but generic stimulus (Chelladurai et al., 1977; Hertel et al., 1999), or with cognitive challenges but with a non-specific or unmeasurable performance response (Abernethy et al., 1999; Berry, 1999; Borgeaud \& Abernethy, 1987; Farrow \& Abernethy, 2002; Farrow et al., 1998; Muir, 1996; Ritchie, 1999; Tenenbaum et al., 1996). Further research to establish a reliable and valid test of agility involving physical performance measures (speed) and perceptual factors is necessary.

\section{References}

Abernethy, B., \& Russell, D. G. (1987). Expert novice difference in an applied selective attention task. Fournal of Sport Psychology, 9, 326345 .

Abernethy, B., Wood, M. J., \& Parks, S. (1999). Can the anticipatory skills of experts be learned by novices? Research Quarterly for Exercise and Sport, 70, 313318.

Alricsson, M., Harns Ringdahl, K., \& Werner, S. (2001). Reliability of sports related functional tests with emphasis on speed and agility in young athletes. Scandinavian fournal of Medicine and Science in Sports, 11, 229232.

Baechle, T. R. (1994). Essentials of strength and conditioning. Champaign, IL: Human Kinetics.

Baker, D. (1999a). A comparison of running speed and quickness between elite professional and young rugby league players. Strength and Conditioning Coach, 7(3), 37.

Baker, D. (1999b). The relation between running speed and measures of strength and power in professional rugby league players. Fournal of Strength and Conditioning Research, 13, 230235.

Barrow, H., \& McGee, R. (1971). A practical approach to measure ment in physical education. Philadelphia, PA: Lea \& Febiger.

Baumgartner, T., \& Jackson, A. (1975). Measurement for evaluation in physical education. Boston, MA: Houghton Mifflin.

Bernier, M. (2003). Perturbation and agility training in the rehabilitation of soccer athletes. Athletic Therapy Today, 8(3), 2022.

Berry, J. T. (1999). Pattern recognition and expertise in Australian football. Unpublished honours thesis, University of Ballarat, Ballarat, VIC.

Besier, T. F., Lloyd, D. G., Ackland, T. R., \& Cochrane, J. L. (2001a). Anticipatory effects of knee joint loading during running and cutting maneuvers. Medicine and Science in Sports and Exercise, 33, 11761181.
Besier, T. F., Lloyd, D. G., Cochrane, J. L., \& Ackland, T. R. (2001b). External loading of the knee joint during running and cutting maneuvers. Medicine and Science in Sports and Exercise, 33, 11681175.

Blazevich, T. (1997a). Resistance training for sprinters (part 1): Theoretical considerations. Strength and Conditioning Coach, 4(3), 912.

Blazevich, T. (1997b). Resistance training for sprinters (part 2): Exercise suggestions. Strength and Conditioning Coach, 5(1), 510.

Bloomfield, J., Ackland, T. R., \& Elliot, B. C. (1994). Applied anatomy and biomechanics in sport. Melbourne, VIC: Blackwell Scientific.

Bompa, T. (1983). Theory and methodology of training. Dubuque, IA: Kendall Hunt.

Booher, L. D., Hench, K. M., Worrell, T. W., \& Stikeleather, J. (1993). Reliability of three single leg hops tests. Fournal of Sport Rehabilitation, 2, 165170.

Borgeaud, P., \& Abernethy, B. (1987). Skilled perception in volleyball defense. Fournal of Sport Psychology, 9, 400406.

Burggemann, G., \& Glad, B. (1990). Time analysis of the sprint events. In B. Glad (Ed.), Scientific Research Project at the Games of the XXIVth Olympiad Seoul 1988 (pp. 11 89). Monaco: International Athletic Foundation.

Buttifant, D., Graham, K., \& Cross, K. (1995). Agility and speed in soccer players are two different performance parameters. Paper presented at the Science and Football IV Conference, Sydney, NSW.

Buttifant, D., Graham, K., \& Cross, K. (1999). Agility and speed in soccer players are two different performance parameters. Paper presented at the Science and Football IV Conference, Sydney, NSW.

Chelladurai, P. (1976). Manifestations of agility. Canadian Associa tion of Health, Physical Education, and Recreation, 42, 3641.

Chelladurai, P., Yuhasz, M., \& Sipura, R. (1977). The reactive agility test. Perceptual and Motor Skills, 44, 13191324.

Clark, S., Martin, D., Lee, H., Fornasiero, D., \& Quinn, A. (1998). Relationship between speed and agility in nationally ranked junior tennis players. Paper presented at the Australian Conference of Science and Medicine in Sport 1998, Adelaide, SA.

Clarke, H. E. (1959). Application of measurement to health and physical education. Englewood Cliffs, NJ: Prentice Hall.

Colby, S., Francisco, A., Yu, B., Kirkendall, D., Finch, M., \& Garrett, W. (2000). Electromyographic and kinematic analysis of cutting maneuvers. American Fournal of Sports Medicine, 28, 234240.

Cox, R. H. (2002). Sport psychology: Concepts and applications (5th edn.). New York: McGraw Hill.

Cronin, J., McNair, P. J., \& Marshall, R. N. (2003). Lunge perfor mance and its determinants. Fournal of Sports Sciences, 21, 4957.

Cureton, T. (1951). Physical fitness of champions. Urbana, IL: University of Illinois Press. 
Delecluse, C. (1997). Influence of strength training on sprint running performance. Sports Medicine, 24, 148156.

Delecluse, C., Van Coppennolle, H., Willem, E., Van Leemputte, M., Diels, R., \& Goris, M. (1995). Influence of high resistance and high velocity training on sprint performance. Medicine and Science in Sports and Exercise, 27, 12031209.

Djevalikian, R. (1993). The relationship between asymmetrical leg power and change of running direction. Unpublished master's thesis, University of North Carolina, Chapel Hill, NC.

Docherty, D., Wenger, H. A., \& Neary, P. (1988). Time motion analysis related to the physiological demands of rugby. fournal of Human Movement Studies, 14, 269277.

Donati, A. (1996). The association between the development of strength and speed. New Studies in Athletics, 2(3), 5158.

Draper, J. A., \& Lancaster, M. G. (1985). The 505 test: A test for agility in the horizontal plane. Australian fournal for Science and Medicine in Sport, 17(1), 1518.

Enoka, R. (2002). Neuromechanics of human movement (3rd edn.). Champaign, IL: Human Kinetics.

Farrow, D., \& Abernethy, B. (2002). Can anticipatory skills be learned through implicit video based perceptual training? fournal of Sports Sciences, 20, 471485.

Farrow, D., Chivers, P., Hardingham, C., \& Sachse, S. (1998). The effect of video based perceptual training on the tennis return of serve. International Fournal of Sport Psychology, 29, 231242.

Francis, C. (1997). Training for speed. Canberra, ACT: Faccioni.

Fulton, K. T. (1992). Off season strength training for basketball. National Strength and Conditioning Association fournal, 14(1), 3133.

Gabbett, T. J. (2002). Physiological characteristics of junior and senior rugby league players. British fournal of Sports Medicine, $36,334339$.

Gambetta, V. (1996). How to develop sport specific speed. Sports Coach, 19(3), 2224.

Gore, C. J. (2000). Physiological tests for elite athletes. Canberra, ACT: Australian Sports Commission.

Hastad, D. N., \& Lacy, A. C. (1994). Measurement and evaluation in physical education and exercise science (2nd edn.). Scottsdale, AZ: Gorsuch Scarisbrick.

Hertel, J., Denegar, C. R., Johnson, P. D., Hale, S. A., \& Buckely, W. E. (1999). Reliability of the cybex reactor in the assessment of an agility task. Fournal of Sport Rehabilitation, 8, 2431.

Hoyle, R. J., \& Holt, L. E. (1983). Comparison of athletes and non athletes on selected neuromuscular tests. Australian Fournal of Sports Sciences, 3, 1318.

Johnson, B. L., \& Nelson, J. K. (1969). Practical measurements for evaluation in physical education. Minneapolis, MN: Burgess.

Johnson, C. (1996). The elastic strength development of Jonathan Edwards. New Studies in Athletics, 11(2 3), 6369.

Keogh, J., Weber, C. L., \& Dalton, C. T. (2003). Evaluation of anthropometric, physiological, and skill related tests for talent identification in female field hockey. Canadian fournal of Applied Physiology, 28, 397409.

Knicker, A. J. (1997). Neuromechanics of sprint specific training skills. Paper presented at the 18th Symposium on Biomechanics in Sport, Denton, TX.

Knight, C., Cohen, D., \& Woodward, C. (2002). The effect of unilateral plyometric, ballistic resistance and agility training on vertical jump ability in the trained and untrained leg. Paper presented at the 12th Commonwealth International Sport Conference, Manchester, UK.

Kuhn, W. (1993). The effects of unilateral and bilateral maximal strength training program upon the bilateral strength index. Paper presented at the International Association of Physical Education and Sport for Girls and Women, Melbourne, VIC.

Kukolj, M., Ropret, R., Ugarkovic, D., \& Jaric, S. (1999). Anthropometric, strength, and power predictors of sprinting performance. Fournal of Sports Medicine and Physical Fitness, 39, 120122.
Kyrolainen, H., Komi, P., \& Belli, A. (1999). Changes in muscle activity patterns and kinetics with increasing running speed. Fournal of Strength and Conditioning Research, 13, 400406.

Luchtenbern, B. (1990). Training for running. Sports, 10(3), 16.

Mann, R. V. (1981). A kinetic analysis of sprinting. Medicine and Science in Sports and Exercise, 13, 325328.

Mathews, D. K. (1973). Measurements in physical education. Philadelphia, PA: W. B. Saunders.

McClay, I., Robinson, J., Andriacchi, T., Frederick, E., Gross, T., Martin, P. et al. (1994). A profile of ground reaction forces in professional basketball. Fournal of Applied Biomechanics, 10, 222236.

Meir, R., Newton, R., Curtis, E., Fardell, M., \& Butler, B. (2001). Physical fitness qualities of professional rugby league football players: Determination of positional differences. Fournal of Strength and Conditioning Research, 15, 450458.

Moreno, E. (1995). Developing quickness part 2. Strength and Conditioning, 17, 3839.

Muir, P. A. (1996). Expertise in surfing: Nature of the perceptual advantage. Unpublished honours thesis, University of Ballarat, Ballarat, VIC.

Murray, P. F. (1996). Psychology and speed. New Studies in Athletics, 11(2 3), 115120.

Negrete, R., \& Brophy, J. (2000). The relationship between isokinetic open and closed kinetic chain lower extremity strength and functional performance. Fournal of Sports Rehabi litation, 9, 4661.

Pandorf, C. E., Nindl, B. C., Montain, S. J., Castellani, J. W., Frykman, P. N., Leone, C. D. et al. (2003). Reliability assessment of two military relevant occupational physical performance tests. Canadian fournal of Applied Physiology, 28, 2737.

Pyne, D. (2001). Testing the athlete. In F. S. Pyke (Ed.), Better coaching: Advanced coach's manual (2nd edn., pp. 77 86). Belconnen, ACT: Human Kinetics.

Reilly, T., Williams, A. M., Nevill, A., \& Franks, A. (2000). A multidisciplinary approach to talent identification in soccer. Fournal of Sports Sciences, 18, 695702.

Rigg, P., \& Reilly, T. (1987). A fitness profile and anthropometric analysis of first and second class rugby union players. In P. Rigg (Ed.), Proceedings of the First World Congress on Science and Football (pp. 194 200). London: E \& FN Spon.

Ritchie, N. (1999). An investigation of pattern recognition anticipation within Australian rules football. Unpublished honours thesis, University of Ballarat, Ballarat, VIC.

Sayers, M. (2000). Running techniques for field sport players. Sports Coach, Autumn, pp. 2627.

Semenick, D. (1990). Tests and measurements: The $\mathrm{T}$ test. National Strength and Conditioning Association fournal, 12(1), 3637.

Sheppard, J. (2003). Strength and conditioning exercise selection in speed development. Strength and Conditioning fournal, 25(4), 2630.

Sheppard, J. (2004). Improving the sprint start with strength and conditioning exercise. Modern Athlete and Coach, 42(4), 913.

Tenenbaum, G., Levy Kolker, N., Sade, S., Lieberman, D., \& Lidor, R. (1996). Anticipation and confidence of decisions related to skilled performance. International fournal of Sport Psychology, 27, 293307.

Tsitskarsis, G., Theoharopoulus, A., \& Garefis, A. (2003). Speed, speed dribble and agility of male basketball players playing in different positions. Fournal of Human Movement Studies, 45, 2130.

Twist, P., \& Benicky, D. (1996). Conditioning lateral movement for multi sport athletes: Practical strength and quickness drills. Strength and Conditioning fournal, 18(5), 1019. 
Webb, P., \& Lander, J. (1983). An economical fitness testing battery for high school and college rugby teams. Sports Coach, 7(3), 4446.

Young, W. B. (1995). Laboratory strength assessment of athletes. New Studies in Athletics, 10(1), 8696.

Young, W. B., Benton, D., Duthie, G., \& Pryor, J. (2001). Resistance training for short sprints and maximum speed sprints. Strength and Conditioning fournal, 23(2), 713.

Young, W. B., Hawken, M., \& McDonald, L. (1996). Relation ship between speed, agility, and strength qualities in Australian rules football. Strength and Conditioning Coach, 4(4), 36.
Young, W. B., James, R., \& Montgomery, I. (2002). Is muscle power related to running speed with changes of direction? Fournal of Sports Medicine and Physical Fitness, 43, 282288.

Young, W. B., McDowell, M. H., \& Scarlett, B. J. (2001). Specificity of sprint and agility training methods. Fournal of Strength and Conditioning Research, 15(3), 315319.

Young, W. B., McLean, B., \& Ardagna, J. (1995). Relationship between strength qualities and sprinting per formance. Fournal of Sports Medicine and Physical Fitness, 35, 1319. 
